\title{
Effects of entrepreneurial orientation on start-up success: A gender perspective
}

\author{
Daisy Mui Hung Kee and Nurulhasanah Abdul Rahman ${ }^{\text {* }}$
}

${ }^{a}$ School of Management, Universiti Sains Malaysia

${ }^{b}$ School of Distance Education, Universiti Sains Malaysia

CHRONICLE A B S TRACT

\section{Article history:}

Received: November 26, 2017

Received in revised format:

March 31, 2018

Accepted: April 4, 2018

Available online:

April 5, 2018

Keywords:

Gender

Entrepreneurial Orientation

Start-up Success

\begin{abstract}
This paper examines the extent to which gender influences on the practice of Entrepreneurial Orientation (EO) on Start-up Success. This study was conducted among Spin-off and Symbiosis Company (SSC) from all sectors in Peninsular Malaysia. Despite the remarkable research on EO and Start-up firms, there is a missing link on how gender provides different perspectives of EO practices among SSC, especially in Malaysia. A total of 120 SSC was chosen and the results show that EO was statistically related to Start-up Success and unveiled the magnitude of change that gender possesses in improving the relationship between EO practice and Start-up Success. The major implication of this study presents the unique contribution of gender in motivating SSC owners to engage in EO. Also, the difference of gender perceptions in business provides a variety of untapped opportunities in terms of entrepreneurial-related practices as different gender perceived different needs and capabilities. Future research is suggested to explore this phenomenon more extensively and develop a comprehensive model for the gender analysis. In brief, the discussion in this paper would help to strengthen the body of knowledge on Entrepreneurship and act as a future reference on SSC, EO, and Start-up Success.
\end{abstract}

\section{Introduction}

During the past few years, there has been tremendous efforts dedicated to entrepreneurship and gender studies (Basyith \& Idris, 2014; Lim \& Envick, 2013; Marlow \& McAdam, 2013). The differences between male and female entrepreneurs are in terms of (not limited to) entrepreneurial intentions, technology-innovation adoption, social engagement, and so forth (Ayub et al., 2013; Goktan \& Gupta, 2015). In the current years, the gender difference on Entrepreneurial Orientation (EO) practices started to attract significant interests among researchers. According to Fellnhofer et al. (2016), females tend to perceive their EO practices less than the males do, but the perceptions on work performance are identical across genders. Kelley et al. (2016) also noted that females tend to be less engaged in entrepreneurial activities as compared with males. However, the authors stated that the gender preferences might differ according to cultures, countries and certain entrepreneurial stages. This notion has motivated this paper to explore the impact of gender on entrepreneurial-related behavior among Malaysian

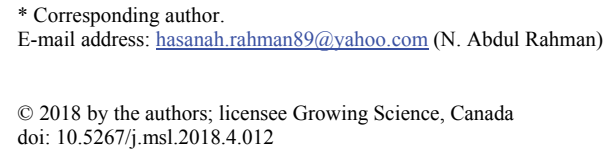


firms specifically on the gender perspectives of EO practices and to what extent it will lead to Start-up Success.

In particular, this study focuses on SSC because these firms are considered as new ventures, without adequate knowledge and funds. Following the definition of SSC from Bocken (2015), SSC is considered as firms at the infantile stage and rely on other organizations' skills, resources, and business strategies to survive. SSC was introduced in Malaysia in 2011 through the Ninth Malaysia Plan (RMK9) as a collaborative effort between the university and industry players. Nevertheless, studies on SSC are considered as an emerging research topic and warrants for more research to be executed in Malaysia. This remainder of this paper is organized as follows. In section 2, the literature review is prepared according to constructs which are EO, Start-up Success, and Gender Perspective. In section 3, the methodology is presented, and findings are illustrated in Section 4. Next, the discussion and conclusions are summarized in the subsequent section. Finally, limitations and future research are provided at the end of this paper.

\section{Literature Review}

Previous literature witnessed that EO had been the most prominent topic as the determinants of firm performance, survival, and success. Despite the outstanding attention on EO, its impact on start-up firms has been largely neglected. As entrepreneurial skills and knowledge are extremely critical to the foundation of a firm in start-up phase, EO is perceived as capable of bridging the skills and knowledge gap to improve the start-up success rate. With that, the following sections are prepared to explain the concept of EO, the definition of Start-up Success, and the gender perspectives on EO practices to improve Start-up Success. In this study, three dimensions of EO are hypothesized to be related to Startup Success, and relationships among these variables are examined.

\subsection{Entrepreneurial Orientation}

To survive and to be successful, start-up firms have to gain a competitive advantage over their competitors and consistently generate positive returns for long-term performance. With this regards, EO plays an important role in shaping the entrepreneurs' thinking styles, behavior, and ideas to be transformed as a comprehensive entrepreneurial skills to outperform the business rivals. EO is defined as the entrepreneurial strategic posture at the firm level to enable sound entrepreneurial decisions and actions (Fellnhofer et al., 2016; Rauch et al., 2009). EO refers to the firm processes, structures, and behaviors characterized by three main dimensions namely; innovativeness, proactiveness, and risk-taking (Covin \& Slevin, 1989; Jamil et al., 2016; Miller, 1983). Also, EO has been referred as strategy-making processes and an approach on how particular business is engaged in entrepreneurial activities ( Lumpkin $\&$ Dess, 2001). More often, EO is regarded as a multi-dimensional construct, and each dimension may have a different relation to the performance variables (Lumpkin \& Dess, 1996; Naldi et al., 2007; Zeebaree \& Siron, 2017; Davari \& Farokhmanesh, 2017). For instance, innovativeness and proactiveness may be positively correlated with higher performance, but risk-taking may have contradicted results. With that, this study follows this notion and treats EO as a multi-dimensional construct. This study leads to the first set of hypotheses of this study as follows:

H1: Innovativeness is positively related to Start-up Success.

H2: Proactiveness is positively related to Start-up Success.

H3: Risk-taking is positively related to Start-up Success.

\subsection{Start-up Success and EO}

Past studies on EO have contributed to the current understanding of entrepreneurship and performance. However, there is a lack of explanation on how different organizational contexts especially start-up firms link to EO. Start-ups are considered as firms with a high degree of risk and uncertainty (Durda \& Krajcik, 2016), thus, require them to engage in EO for a more reliable and consistent business direction. Similarly, Ghosh and Bhowmick (2014) indicated that uncertainty in entrepreneurship is critical to the 
entrepreneurs as it is directly related to the context of decision-making. Any mistake or oversight at the start-up phase may jeopardize the firm's future. This is where EO is needed the most. The authors also added that it is important for the start-up firms to understand the EO concept for their future growth and survival. In the same view, previous scholars argued that higher level of EO practices leads to superior performance (Naldi et al., 2007; Zeebaree \& Siron, 2017), improve business growth (Amin et al., 2016; Johansen, 2013) and increase survival rates (Adomako et al., 2016; Shehu \& Mahmood, 2015). Indeed, EO is regarded as a competitive advantage and inevitable for firms, regardless of their sizes and industries to survive in the market place. The positive impact of EO on firm performance reflects the possible change it might bring to the start-up firms. The predictors of Start-up Success are mainly related to the efforts carried out to ensure a firm to be financially stable and resilient within the first five years (Janáková, 2015). Some authors even labeled it as the preparation for 'valley of death.' Indeed, the authors asserted that EO is best to described as the strategic entrepreneurial practices that firms need to overcome such drawback.

\subsection{Gender Perspective}

In general, the number of female entrepreneurs is exceeding the male entrepreneurs in Malaysia (Ong et al., 2016). Quoting studies by Vossenberg (2013) and Musa et al. (2016), the higher number of female in business represents a dynamic workforce, especially in entrepreneurship. In the past, the entrepreneurs were mainly male entrepreneurs in the field of electronics, hardware, and technology. Nowadays, as the globalization era is expanding, the majority of start-up firms are owned by a female (Ong et al., 2016). The establishment of the online businesses is mostly dominated by female entrepreneurs as they prefer to engage in cottage-based industries which require the use of basic technology (Hoe et al., 2012; Surin et al., 2015). Moving to a wider angle, gender difference does exist in terms of EO practices as studied by Bertoncelj and Kovac (2009), Fellnhofer et al. (2016) and Kelley et al. (2016). These authors found that females had higher tendency to engage in EO practices than males did. On the contrary, Goktan and Gupta (2015) found that males were more prone to practice higher EO and achieve superior performance. Despite the extensive review on EO and performance relationship in many countries, the gender impacts on EO practices are rare and inadequate (Fellnhofer et al., 2016; Priya \& Sreeranganadhan, 2017). Also, scarcity of previous research to relate EO and Start-up Success portrayed that the understanding of these two ideas is limited (Janáková, 2015). These loopholes open-up a new gap to be filled with more studies, especially within the local context. On the basis of previous studies on EO and gender analysis, this study anticipates that EO practices vary between male and female entrepreneurs, and also shed lights on how EO is positively associated with Start-up Success. The findings of this study will be among the pioneer in evaluating the impact of EO on Startup Success according to gender by using Partial Least Square-Structural Equation Modeling (PLSSEM). Based on the literature reviewed the research model was developed as presented in Fig. 1.

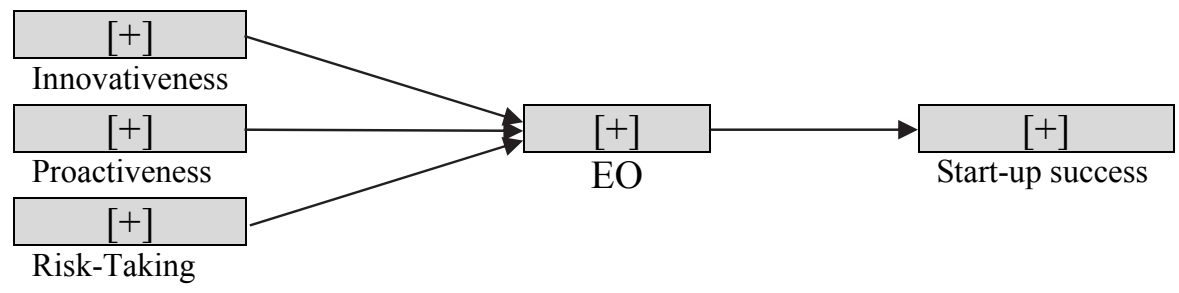

\section{Methodology}

Fig. 1. Research Framework

The present study focused on Malaysian firms to validate the research model on the difference of EO practices between genders. To analyze this relationship, SSC owners who own a firm in Peninsular Malaysia were requested to participate in this study. A sample of 120 firms was randomly selected from a database from Malaysian Technology Development Corporation (MTDC) and Research University 
(RU). The data was collected using self-administered questionnaires from July to August 2016. Usable responses were received from 79 firms yielding $65.8 \%$ of response rate.

The constructs were measured using the established multiple items and scales from previous literature. Constructs in this study were measured using previous operationalized items such as EO with 13 indicators adapted from Fellnhofer et al. (2016) and Start-up Success with 18 indicators adapted from Zhou and Wit (2009). Each item was measured on a seven-point Likert scale anchored from "Strongly disagree" to "Strongly agree". Also, the items were modified using the technique of adopting and adapt to fit the Malaysian context. Of these 79 firms, $43 \%$ of the respondents were male, and $40 \%$ of them maintained at least Bachelor's Degree. In terms of job position, $58 \%$ of the respondents were the firm's owner and $22 \%$ reported as the firm's manager. The remaining $20 \%$ was the firm's representative in completing the questionnaires. In general, the sample firms fit the profiles of micro businesses as $57 \%$ was reported to have less than five full-time employees and the rest employed less than 30 employees who indicated as small businesses.

\section{Results and Findings}

To analyze the research model, this study utilized Structural Equation Modeling (SEM) with Partial Least Square (PLS) approach using the SmartPLS version 3.2.6 software (Ringle et al., 2015). In addition, to carry out a multi-group analysis, PLS-SEM is more appropriate to explore the differences between EO practices according to gender. There are two main assessments in PLS-SEM namely; Measurement Model and Structural Model. According to Hair et al. (2016), the item's outer loadings, Average Variance Extracted (AVE), and Composite Reliability (CR) are used to assess the Measurement Model (see Table 1).

Table 1

Results of Measurement Model

\begin{tabular}{lll}
\hline Variable & CR & AVE \\
\hline EO & 0.948 & 0.573 \\
Innovativeness & 0.904 & 0.703 \\
Proactiveness & 0.895 & 0.641 \\
Risk-Taking & 0.931 & 0.734 \\
Start-up Success & 0.916 & 0.504 \\
\hline
\end{tabular}

In this study, two items (EO3 and SP4) were deleted due to low loadings. After deletion, the outer loadings of the items were ranged from 0.534 to 0.921 . These results indicated that loadings of the items were verified for further analysis. The AVE of all the constructs exceeded the cut-off value of 0.5 as suggested in the literature (Hair et al., 2014). Also, the CR values of the constructs were found to have a minimum threshold of 0.7 . Next, the discriminant validity of the model was analyzed. The results showed that the outer loadings on correlated constructs are greater than all of the loadings on other constructs suggesting that the required discriminant validity was achieved (see Table 2). After testing Measuring Model, the Structural Model has been analyzed. The $\mathrm{R}^{2}$ and the path coefficients have indicated how well the data supported the hypothesized model. The bootstrapping method with a re-sampling of 5000 was employed to estimate the significance of the path coefficients.

\section{Table 2}

Results of Discriminant Validity

\begin{tabular}{llllll}
\hline & $\mathbf{1}$ & $\mathbf{2}$ & $\mathbf{3}$ & $\mathbf{4}$ & $\mathbf{5}$ \\
\hline EO & $\mathbf{0 . 9 5 7}$ & & & & \\
Innovativeness & 0.839 & $\mathbf{0 . 8 4 4}$ & & & \\
Proactiveness & 0.757 & 0.744 & $\mathbf{0 . 8 5 8}$ & & \\
Risk-Taking & 0.921 & 0.610 & 0.800 & $\mathbf{0 . 8 5 7}$ & \\
Start-up Success & 0.710 & 0.739 & 0.752 & 0.735 & $\mathbf{0 . 8 1 9}$ \\
\hline
\end{tabular}


In this study, the Structural Model confirmed the relationship between EO and Start-up Success. The results of $\mathrm{R}^{2}$ value was 0.671 suggesting that $67.1 \%$ of the variance in Start-up Success could be explained by EO (see Table 3 ).

Table 3

Results of Structural Model

\begin{tabular}{|c|c|c|c|c|c|}
\hline Variable & Path Coefficient & $\mathbf{R}^{2}$ & t-value & $f^{2}$ & $Q^{2}$ \\
\hline EO $\rightarrow$ Start-up Success & 0.819 & \multirow{4}{*}{0.671} & $54.978 * *$ & - & \multirow{4}{*}{0.353} \\
\hline H1: Innovativeness $\rightarrow$ Start-up Success & 0.321 & & $14.355^{* *}$ & 0.1820 & \\
\hline H2: Proactiveness $\rightarrow$ Start-up Success & 0.366 & & $29.307 * *$ & 0.0161 & \\
\hline H3: Risk-Taking $\rightarrow$ Start-up Success & 0.411 & & $20.639 * *$ & 0.0161 & \\
\hline EO (Male) $\rightarrow$ Start-up Success & 0.874 & 0.764 & $41.248 * *$ & - & 0.300 \\
\hline EO (Female) $\rightarrow$ Start-up Success & 0.807 & 0.652 & $33.323 * *$ & - & 0.287 \\
\hline
\end{tabular}

Note: $* \mathrm{p}<0.05, * * \mathrm{p}<0.01$

There was a positive relationship $(\beta=0.321, \mathrm{p}<0.01)$ between innovativeness and Start-up Success which supported the H1. Accordingly, the relationship between proactiveness $(\beta=0.366, p<0.01)$ and risk taking $(\beta=0.411, \mathrm{p}<0.01)$ towards Start-up Success also yielded significant results. Thus, it confirmed that $\mathrm{H} 2$ and $\mathrm{H} 3$ were supported. The effect size $\left(f^{2}\right)$ was also calculated to measure the impact of EO on Start-up Success. The $f^{2}$ of innovativeness is 0.1820 and regarded as a medium effect, while the $f^{2}$ of proactiveness and risk-taking are 0.0161 which represent small effect sizes (Hair Jr et al., 2016). The $Q^{2}$ value is 0.353 suggesting that the model has large predictive relevance. By comparison between genders, EO practices for male showed slightly higher $\mathrm{R}^{2}\left(\mathrm{R}^{2}=0.764\right)$ suggesting that $76.4 \%$ of the EO impact practiced by male owners/managers statistically improves the Start-up Success.

\section{Table 4}

Results of PLS-MGA

\begin{tabular}{llll}
\hline Variable & t-value & Difference (male/female) & Higher results \\
\hline $\mathrm{EO} \rightarrow$ Start-up Success & $4.716^{* *}$ & Yes & Male \\
$:$ Innovativeness $\rightarrow$ Start-up Success & $9.051^{*}$ & Yes & Male \\
$:$ Proactiveness $\rightarrow$ Start-up Success & $4.191^{* *}$ & Yes & Male \\
$:$ Risk-Taking $\rightarrow$ Start-up Success & $3.353^{*}$ & Yes & Female \\
\hline
\end{tabular}

Note: ${ }^{*} \mathrm{p}<0.05, * * \mathrm{p}<0.01$

To explore the differences, PLS Multi-Group Analysis (PLS-MGA) was carried out between male and female sub-samples (Sarstedt et al., 2011). The differences between the path coefficients were tested across the respective two data sets, and it revealed that the relationship differs significantly according to gender (see Table 4). These results indicated that both data sets have statistically significant differences as EO practices by male respondents explained a higher variance of Start-up Success than the female respondents did (see Fig. 2).

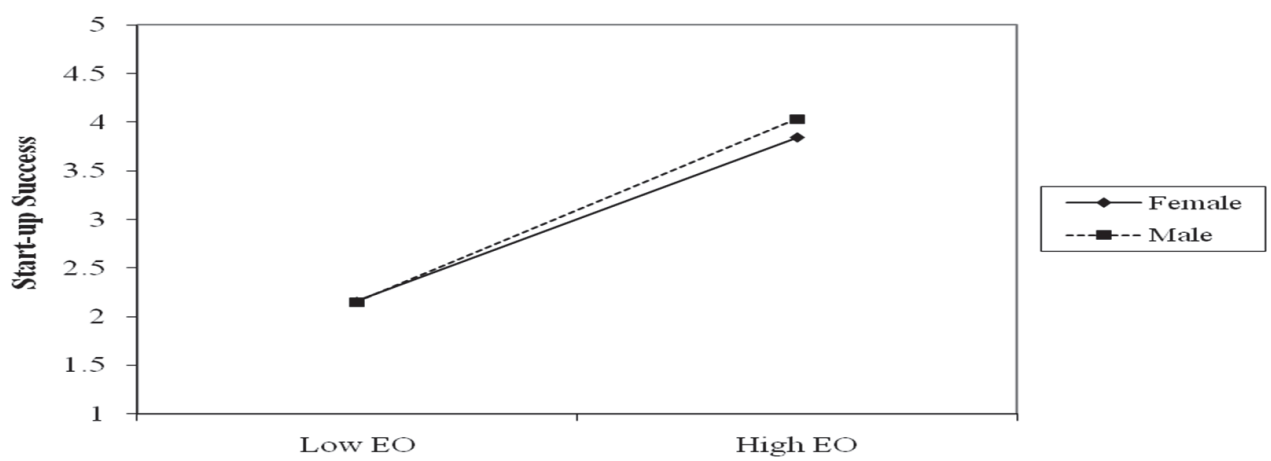

Fig. 2. Difference male and female 


\section{Discussion and Conclusions}

The main objective of this study was achieved through the relationship between EO and Start-up Success, which revealed a significant relationship. The findings in this study also confirmed the established link between EO and Performance as extensively been researched worldwide. This study contributes to the prior literature by integrating the EO relationship with Start-up Success. Despite the extant literature on EO, very limited studies have focused on the start-up firms. The start-up firms are the important assets for Malaysia as their profit-making businesses are the backbone of Malaysia economic growth. Indeed, this paper is the pioneer to study the EO practices according to gender using the original conceptualization of EO (Miller, 1983), which are innovativeness, proactiveness, and risk-taking towards Start-up Success using PLS-SEM and PLS-MGA approach.

Shedding further lights on the EO sphere, the gender impact on EO practices is enlightening. The difference of EO practices between male and female have been evaluated, and the empirical evidence revealed that EO practices vary according to gender. This study discovered that the male owners/managers were proved to develop a slightly higher chance of Start-up Success as compared with female owners/managers. This finding is aligned with studies by Ronay and Kim (2006), and Johansen (2013) who noted male entrepreneurs performed better than female entrepreneurs. Contrary to the previous literature on gender differences, especially in entrepreneurship studies found that female entrepreneurs were prone to improve higher performance (see Ong et al., 2016; Tewari \& Malhotra, 2014). These authors noted that female entrepreneurs had a higher motivation to survive, willing to learn about entrepreneurial knowledge, and possess better financial control.

In a different view, it can be deduced that most of past studies on gender analysis from the 1990s to the early years of 2000 s, showed the tendency of male entrepreneurs to be more successful than female entrepreneurs (Bertoncelj \& Kovač, 2009; Kirkwood, 2009). However, specifically in 2010 onwards, most of the current studies have revealed that the female entrepreneurs were proved to have a higher chance of business success/performance (Fellnhofer et al., 2016; Ong et al., 2016). The reasons are mostly due to the higher cost of living, the increase of female empowerment, the propensity to earn own money/salary, to complement the household income, and so forth (Kelley et al., 2016). However, as this study obtained different findings, it may be explained by some possibilities at present. For instance, by looking at the specific dimensions of EO, male entrepreneurs are prone to practice EO higher than the female entrepreneurs regarding innovativeness and proactiveness. They prefer to work innovatively, encourage employees to generate business ideas, and actively seek for a new method to improve business performance. Thus, they explained the tendency for the male entrepreneurs to dominate the market industry.

Even after decades of research on EO and Performance, there are still many unanswered questions and scarce resources about why some firms performed well and why some other failed to survive. Thus, the major implication of this paper is to emphasize the role of gender in improving Start-up Success through EO practices. As discussed earlier, there is an augmented debate on which gender is a better predictor of performance (Fellnhofer et al., 2016; Runyan et al., 2006; Tewari \& Malhotra, 2014). However, future research needs to be directed to further develop this model, especially on EO practices by both genders managing a firm to ensure EO potentials are well-utilized. In fact, Zimmerman and Brouthers (2012) argued that the combination of firms that owned/managed by male and female is a better solution to increase financial and non-financial performance. Further, researchers have noted that heterogeneous genders may improve the firm's decision making via advocacy, training, and team coaching (Fellnhofer et al., 2016; Joshi \& Roh, 2009). In fact, policy-makers may consider these findings by suggesting a gender mix management for start-up firms to encourage a sound decision-making and improve firm performance. 


\section{Limitations and Future Research}

We acknowledge some limitations in this study. First, this paper is cross- sectional in nature. Thus, future research might consider applying a longitudinal study to establish the extent to which the hypothesized relationships might be causal. Second, the use of larger sample size may provide more statistical power for detecting our hypothesized effects. Another suggestion is to conduct comparative studies across business sizes, industries, and countries to further understand the constructs used in this study.

\section{References}

Adomako, S., Narteh, B., Danquah, J. K., \& Analoui, F. (2016). Entrepreneurial orientation in dynamic environments: the moderating role of extra-organizational advice. International Journal of Entrepreneurial Behavior \& Research, 22(5), 616-642.

Amin, M., Thurasamy, R., Aldakhil, A. M., \& Kaswuri, A. H. B. (2016). The effect of market orientation as a mediating variable in the relationship between entrepreneurial orientation and SMEs performance. Nankai Business Review International, 7(1), 39-59.

Ayub, A., Razzaq, A., Aslam, M. S., \& Iftekhar, H. (2013). Gender effects on entrepreneurial orientation and value innovation: evidence from Pakistan. European Journal of Business and Social Sciences, 2(1), 82-90.

Basyith, A., \& Idris, M. (2014). The Gender Effect on Small Business Enterprises' Firm Performance: Evidence from Indonesia. Indian Journal of Economics and Business, 13(1).

Bertoncelj, A., \& Kovač, D. (2009). Gender difference in the conative componet of entrepreneurial orientation. Journal for East European Management Studies, 14(4), 357-368.

Bocken, N. (2015). Sustainable venture capital-catalyst for sustainable start-up success? Journal of Cleaner Production, 108, 647-658.

Covin, J. G., \& Slevin, D. P. (1989). Strategic management of small firms in hostile and benign environments. Strategic management journal, 10(1), 75-87.

Davari, A., \& Farokhmanesh, T. (2017). Impact of entrepreneurship policies on opportunity to startup. Management Science Letters, 7(9), 431-438.

Durda, L., \& Krajcik, V. (2016). The role of networking in the founding and development of start-up technology companies. Polish Journal of Management Studies, 14(2).

Fellnhofer, K., Puumalainen, K., \& Sjögrén, H. (2016). Entrepreneurial orientation and performance-are sexes equal? International Journal of Entrepreneurial Behavior \& Research, 22(3), 346-374.

Ghosh, S., \& Bhowmick, B. (2014). Uncertainties in Entrepreneurship Climate: A Study on Start-ups in India. Procedia-Social and Behavioral Sciences, 150, 46-55.

Goktan, A. B., \& Gupta, V. K. (2015). Sex, gender, and individual entrepreneurial orientation: evidence from four countries. International Entrepreneurship and Management Journal, 11(1), 95-112.

Hair Jr, J. F., Hult, G. T. M., Ringle, C., \& Sarstedt, M. (2016). A primer on partial least squares structural equation modeling (PLS-SEM): Sage Publications.

Hoe, C. H., Isa, F. M., Hin, C. W., Hashim, N., Yunus, J. M., \& Abdullah, H. H. (2012). Development of women entrepreneurs: the case of Malaysia. World, 2(6).

Jamil, F., Ismail, K., Siddique, M., Khan, M. M., Kazi, A. G., \& Qureshi, M. I. (2016). Business incubators in asian developing countries. International Review of Management and Marketing, 6(4S).

Janáková, H. (2015). The Success Prediction of the Technological Start-up Projects in Slovak Conditions. Procedia Economics and Finance, 34, 73-80.

Johansen, V. (2013). Entrepreneurship education and start-up activity: a gender perspective. International Journal of Gender and Entrepreneurship, 5(2), 216-231.

Joshi, A., \& Roh, H. (2009). The role of context in work team diversity research: A meta-analytic review. Academy of Management Journal, 52(3), 599-627.

Kelley, D., Singer, S., \& Herrington, M. (2016). 2015/16 global report. GEM Global Entrepreneurship Monitor, Babson College, Universidad del Desarrollo, Universiti Tun Abdul Razak, Tecnológico de Monterrey, London Business School, Babson Park, MA, Santiago, London.

Kirkwood, J. (2009). Motivational factors in a push-pull theory of entrepreneurship. Gender in Management: An International Journal, 24(5), 346-364.

Lim, S., \& Envick, B. R. (2013). Gender and entrepreneurial orientation: a multi-country study. International Entrepreneurship and Management Journal, 9(3), 465-482. 
Lumpkin, G. T., \& Dess, G. G. (1996). Clarifying the entrepreneurial orientation construct and linking it to performance. Academy of management Review, 21(1), 135-172.

Lumpkin, G. T., \& Dess, G. G. (2001). Linking two dimensions of entrepreneurial orientation to firm performance: The moderating role of environment and industry life cycle. Journal of business venturing, 16(5), 429-451.

Marlow, S., \& McAdam, M. (2013). Gender and entrepreneurship: Advancing debate and challenging myths; exploring the mystery of the under-performing female entrepreneur. International Journal of Entrepreneurial Behavior \& Research, 19(1), 114-124.

Miller, D. (1983). The correlates of entrepreneurship in three types of firms. Management Science, 29(7), 770 791.

Musa, M., Shuib, R., Selamat, N. H., Mohd Isa, S., Osman, I., \& Abu Bakar, S. (2016). A Study Of Women Micro Entrepreneurs In Malaysia: Livelihood Strategies And Challenges.

Naldi, L., Nordqvist, M., Sjöberg, K., \& Wiklund, J. (2007). Entrepreneurial orientation, risk taking, and performance in family firms. Family Business Review, 20(1), 33-47.

Ong, S. Y. Y., Habidin, N. F., Salleh, M. I., \& Fuzi, N. M. (2016). Relationship of Entrepreneurship Practice and Business Performance of Women Entrepreneur in Malaysia. International Journal of Academic Research in Business and Social Sciences, 6(11), 95-109.

Priya, S., \& Sreeranganadhan, K. D. (2017). Gender Issues and Challenges of Fisherwomen to Become an Entrepreneur in Kerala. Paper presented at the Proceedings of International HR Conference.

Rauch, A., Wiklund, J., Lumpkin, G. T., \& Frese, M. (2009). Entrepreneurial orientation and business performance: An assessment of past research and suggestions for the future. Entrepreneurship theory and practice, 33(3), 761-787.

Ringle, C. M., Wende, S., \& Becker, J.-M. (2015). SmartPLS 3. Boenningstedt: SmartPLS GmbH, http://www. smartpls. com.

Ronay, R., \& Kim, D. Y. (2006). Gender differences in explicit and implicit risk attitudes: A socially facilitated phenomenon. British Journal of Social Psychology, 45(2), 397-419.

Runyan, R. C., Huddleston, P., \& Swinney, J. (2006). Entrepreneurial orientation and social capital as small firm strategies: A study of gender differences from a resource-based view. The International Entrepreneurship and Management Journal, 2(4), 455.

Sarstedt, M., Henseler, J., \& Ringle, C. M. (2011). Multigroup analysis in partial least squares (PLS) path modeling: Alternative methods and empirical results. In Measurement and research methods in international marketing (pp. 195-218): Emerald Group Publishing Limited.

Shehu, A. M., \& Mahmood, R. (2015). The Moderating Role of Business Environment in the Relationship between Entrepreneurial Orientation and Business Performance among Nigerian SMEs. Jurnal Pengurusan (UKM Journal of Management), 43.

Surin, E. F., Halil, N. H. A., \& Edward, O. T. (2015). The Comparative Analysis of Gender and Social Network among Malay SMEs Entrepreneurs in Malaysia. Journal of Economics, Business and Management, 3(7), 715718.

Tewari, V., \& Malhotra, S. B. (2014). Outlook of women entrepreneurs running small business: How skills as a major factor affecting performance and growth of women entrepreneurs in India?

Vossenberg, S. (2013). Women Entrepreneurship Promotion in Developing Countries: What explains the gender gap in entrepreneurship and how to close it. Maastricht School of Management Working Paper Series, 8, 127.

Zeebaree, M. R. Y., \& Siron, R. B. (2017). The Impact of Entrepreneurial Orientation on Competitive Advantage Moderated by Financing Support in SMEs. International Review of Management and Marketing, 7(1).

Zhou, H., \& de Wit, G. (2009). Determinants and dimensions of firm growth.

Zimmerman, M. A., \& Brouthers, K. D. (2012). Gender heterogeneity, entrepreneurial orientation and international diversification. International Journal of Gender and Entrepreneurship, 4(1), 20-43.

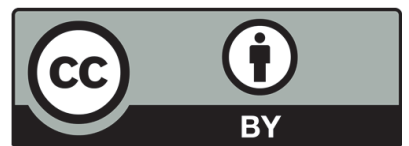

(C) 2018 by the authors; licensee Growing Science, Canada. This is an open access article distributed under the terms and conditions of the Creative Commons Attribution (CC-BY) license (http://creativecommons.org/licenses/by/4.0/). 